\title{
Structure of the Intraspinal Projections of Single, Identified Muscle Spindle Afferents from Neck Muscles of the Cat
}

\author{
S. A. Keirstead ${ }^{a}$ and P. K. Rose \\ Department of Physiology, Queen's University, Kingston, Ontario K7L 3N6, Canada
}

The morphology and frequency of collaterals originating from single afferents supplying primary endings of muscle spindles in dorsal neck muscles have been examined using intraaxonal injections of HRP. Within the segment in which the afferent entered the spinal cord, one collateral was found for every $3.3 \mathrm{~mm}$ of stained axon. In contrast, afferentsone of more segments rostral to the segment in which they entered the spinal cord-had fewer collaterals: One collateral was found for every $\mathbf{6 . 3} \mathrm{mm}$ of stained axon. The branching structure and terminal distribution of the collaterals were generally similar regardless of the muscle from which the afferent originated and the segment in which the collateral was found. Boutons were found in 2 zones: One of these was located in the intermediate zone, within and around the central cervical nucleus, and the other was found in laminae VIII and IX, including the motoneuron nuclei. The ventral termination zone of collaterals in the same segment as their parent axon entered the spinal cord was larger and had more boutons than the same projection of collaterals whose parent axon entered the spinal cord 1 or 2 segments caudal to the segment in which the collateral was found.

These results indicate that afferents supplying primary endings of neck muscle spindles are more likely to contact neurons in the same segment in which the afferent enters the spinal cord than in more rostral segments. However, even within the same segment in which the afferent enters the spinal cord, the projection of neck muscle afferents to the ventral horn is less dense than the corresponding projection of hindlimb muscle spindle afferents in the lumbosacral spinal cord.

Despite the remarkably large number, and correspondingly high density, of muscle spindles found in dorsal neck muscles compared with most other muscles in the cat (Richmond and Abrahams, 1975), it has been difficult to discern the effects that muscle spindle afferents have at the level of the upper cervical spinal cord. Electrophysiological experiments have shown that low-threshold neck muscle afferents either have a less potent

\footnotetext{
Received Sept. 29, 1987; revised Dec. 21, 1987; accepted Dec. 28, 1987.

This research was supported by the Canadian Medical Research Council and the Botterell Foundation at Queen's University. S. A. K. was funded by an Ontario Graduate Scholarship. We wish to thank Monica Neuber for excellent technical assistance, Wendy Brown for preparation of the manuscript, and Drs. Abrahams, Richmond, and Zarzecki for their comments on earlier versions of this report.

Correspondence should be addressed to Dr. P. K. Rose, Department of Physiology, Queen's University, Botterell Hall, Room 432, Kingston, Ontario K71 3 N6, Canada.

a Present address: Neuroscience Unit, Montreal General Hospital, McGill University, 1650 Cedar Avenue, Montred, P. Q., H3G 1A4 Canada.

Copyright (C) 1988 Society for Neuroscience $0270-6474 / 88 / 093413-14 \$ 02.00 / 0$
}

effect or do not participate in classical segmental pathways that have been demonstrated in the lumbosacral spinal cord. For example, stimulation of upper cervical (C2-C4) dorsal roots does not usually evoke a perceptible reflex discharge in the corresponding ventral roots (Abrahams et al., 1975; Ezure et al., 1978). Intracellular recordings from dorsal neck motoneurons-biventer cervicis (BC), complexus (CM) and splenius (SP) - have revealed a monosynaptic connection (Wilson and Maeda, 1974; Anderson, 1977), but the EPSPs evoked by electrical stimulation of low-threshold neck muscle afferents are small (mean amplitude, $400 \mu \mathrm{V}$ : Rapoport, 1979; 350-3100 $\mu \mathrm{V}$ : Brink et al., 1981) compared with those observed in hindlimb motoneurons (2.0-12.0 mV: Eccles et al., 1957). Furthermore, muscle afferents from SP evoke EPSPs only in those SP motoneurons that lie in the same segment as their dorsal root entry and in those that lie in more rostral segments (Brink et al., 1981). This asymmetric distribution of the monosynaptic connection is more distinct than the homonymous connections of nerves innervating different regions of individual hindlimb muscles (Botterman et al., 1983a, b; Lucas and Binder, 1984; Hamm et al., 1986; Vanden Noven et al., 1986).

Not only are the direct connections between neck muscle afferents and motoneurons unusual, but several polysynaptic connections appear to be absent in the upper cervical spinal cord. Specifically, it has not been possible to demonstrate crosscd disynaptic inhibition (Anderson, 1977) in neck muscle motoneurons or a reciprocal inhibitory link between dorsal neck muscle afferents and motoneurons innervating their antagonist, sternocleidomastoid (Rapoport, 1979).

Anatomical studies have provided more positive, yet limited information regarding the spinal targets of neck muscle spindle afferents. Afferent projections to the upper cervical spinal cord have been extensively studied with degeneration techniques in a variety of species (cat: Ranson et al., 1932; Escolar, 1948; Szentagothai, 1948; Imai, 1964; Imai and Kusama, 1969; Wiksten and Grant, 1983; Takahashi et al., 1985; monkey: Corbin et al., 1937; Shriver et al., 1968; rabbit: Yee and Corbin, 1939). However, since the entire dorsal root was severed, these experiments revealed the terminal distribution of afferents originating from many different types of sensory receptors in both muscle and skin. The recent introduction of transganglionic transport of HRP enabled Abrahams et al. (1984b) and Nyberg and Blomqvist (1984) to label selectively the central projections of afferents that originate from dorsal neck muscles. These studies demonstrated that muscle afferents from $\mathrm{BC}$ and $\mathrm{CM}$ project to the intermediate region of the gray matter, within and around the central cervical nucleus (CCN). The projections of afferents supplying dccp ncck muscles have a similar distribution (Ammann et al., 1983; Bakker et al., 1984) and are consistent with 
the results of electrophysiological studies demonstrating monosynaptic connections from low-threshold neck muscle afferents onto neurons in and around the CCN (Hirai et al., 1978, 1984; Abrahams et al., 1979). However, afferent projections to the ventral horn could not be assessed using transganglionic transport of HRP because the afferent terminals could not be distinguished from the axonal and dendritic profiles of motoneurons that had been retrogradely labeled (Abrahams et al., 1984b). Moreover, the projections of afferents innervating different types of muscle receptors could not be distinguished.

In the present experiments, the morphology of the intraspinal projections of single, identified neck muscle spindle afferents was examined using intra-axonal injections of HRP. This technique has provided detailed descriptions of the structure of identified muscle afferents in the lumbosacral spinal cord (Brown and Fyffe, 1978, 1979; Ishizuka et al., 1979; Conradi et al., 1983; Tracey and Walmsley, 1984; Hongo et al., 1987) and dorsal column nuclei (Fyffe et al., 1986). Recently, Hirai et al. (1984), as part of a study of the peripheral input to spinocerebellar tract cells in $\mathrm{CCN}$, briefly described the structure of several collaterals of single neck muscle afferents intracellularly stained with HRP. These afferents were excited by low-threshold electrical stimulation of nerves innervating $\mathrm{BC}, \mathrm{CM}$, or SP and, therefore, likely originated from primary endings of muscle spindles. The axons gave rise to collaterals that terminated in the $\mathrm{CCN}$ and ventral horn. We have used different criteria to identify afferents from primary endings of muscle spindles and have confirmed the observations of Hirai et al. (1984). In addition, we have compared the frequency of collaterals and the 3-dimensional distribution and density of boutons on collaterals in segments at the same level and rostral to the segment where the afferent entered the spinal cord. Preliminary accounts of some of the results of this study have been reported previously (Keirstead and Rose, 1983a, 1984; Rose and Keirstead, 1986).

\section{Materials and Methods}

Surgical preparation. Data were obtained from 22 adult cats $(2.4-4.4$ $\mathrm{kg}$ ) that were anesthetized either with alpha-chloralose $(70 \mathrm{mg} / \mathrm{kg}, \mathrm{i} . \mathrm{v}$.) following induction with ethyl chloride and ether or with sodium pentobarbital (Somnotol, MTC; $35 \mathrm{mg} / \mathrm{kg}$, i.p.; supplementary doses, $5 \mathrm{mg}$ / $\mathrm{kg}$, i.v., were administered to maintain anesthesia). The dorsal neck muscles were separated by an incision along the midline ligament and gently retracted to expose the cervical vertebral column. Care was taken to minimize trauma to the large dorsal and lateral neck muscles throughout this procedure. A laminectomy was performed from $\mathrm{Cl}$ to $\mathrm{C} 5$, and the head and vertebral column were secured in a stereotaxic and spinal frame. The spinal cord was submerged in silicone oil warmed to $37^{\circ} \mathrm{C}$.

The $\mathrm{C} 2, \mathrm{C} 3$, and $\mathrm{C} 4$ nerve branches to $\mathrm{SP}, \mathrm{BC}$, and $\mathrm{CM}$, respectively, were isolated bilaterally, and each was placed on bipolar stimulating electrodes. The segmental nerves supplying $\mathrm{BC}$ and $\mathrm{CM}$ travel together (Richmond and Abrahams, 1975; Abrahams et al., 1984a) and are difficult to separate with certainty and without causing damage. As a result, the afferents that were directly excited by stimulation of nerve branches to $\mathrm{BC}$ and $\mathrm{CM}$ will be referred to as BCCM afferents.

The cats were paralyzed with gallamine triethiodide (Flaxedil, Poulenc; $2.5-5.0 \mathrm{mg} / \mathrm{kg} / \mathrm{hr}$ ) and artificially respirated. The dose of Flaxedil was equal to that reported to produce intrafusal and extrafusal blockade in hindlimb muscle (Carli et al., 1967). Although Chan et al. (1987) have recently found that injections of $3 \mathrm{mg} / \mathrm{kg} / \mathrm{hr}$ of gallamine triethiodide may fail to block intrafusal activity completely in perivertebral muscles, we found no relationship between the degree of variability of instantaneous frequency (an index of intrafusal block, cf. Matthews and Stein, 1969) and the time at which the gallamine triethiodide was administered. Hence, in the present experiments, blockade of intrafusal activity appeared to be complete and stable. A bilateral pneumothorax was performed to reduce respiratory-related movements. End-tidal $\% \mathrm{CO}_{2}$ was monitored with a medical gas analyzer (LB-2, Beckman) and main- tained at $3.5-4.0 \%$ by adjusting tidal volume and respiratory rate. Dextran (Macrodex, Pharmacia, 6\%) or lactated Ringers (Baster, Travenol) were often infused intravenously. Rectal temperature was monitored and maintained at $37 \pm 1^{\circ} \mathrm{C}$ with a feedback-controlled heating pad.

Intra-axonal injections of HRP. Glass microelectrodes (Kwik-Fil, W.P. Instrument) were back-filled with $10-20 \% \mathrm{HRP}$ (Boehringer) in $0.05 \mathrm{M}$ Tris- $\mathrm{HCl}$ buffer to which was added $\mathrm{KCl}$ to a final concentration of $0.2 \mathrm{M} \mathrm{KCl}$ (Snow et al., 1976). One drop of wetting solution (Photoflo 200. Eastman-Kodak Co.) was added to 50-70 $\mu \mathrm{l}$ of the HRP solution (Deschenes et al., 1979), and the electrode tips were immersed in the $\mathrm{KCl}$-Tris solution overnight to facilitate complete filling of the tips. The electrodes were then beveled (Sutter Instrument Co.) to yield tips with a diameter of $1-2 \mu \mathrm{m}$. The initial DC resistances of these electrodes ranged from 3-13 $\mathrm{M} \Omega$.

Intra-axonal recordings were made in the dorsal columns just medial to the dorsal root entry zone of $\mathrm{C} 2, \mathrm{C} 3$, and $\mathrm{C} 4$. The spontaneous activity of each neck muscle afferent was recorded on FM tape, and the mean and range of instantaneous discharge frequencies were determined from interspike interval histograms compiled over 1-3 sec. For several reasons it was not possible to identify afferents from primary endings of muscle spindles according to the conventional criteria (Matthews, 1972), such as their responses to muscle stretch or muscle contraction. Intraaxonal penetrations could not be maintained during contraction or manipulation of the neck muscles due to the close proximity of dorsal neck muscles and the vertebral column. Moreover, the conduction velocity of afferents innervating primary and secondary endings of muscle spindles in BC and CM overlap (Richmond and Abrahams, 1979). Therefore, axons were considered to innervate primary endings of neck muscle spindles if (1) they were directly excited by stimulation of a neck muscle nerve, (2) they were tonically active when the muscles were at or below resting length, and (3) their instantaneous discharge frequency varied by $6 \%$ or more of the mean frequency when the muscles were at or below resting length. It is well established that neck muscle spindle afferents are spontaneously active at their resting length (Richmond and $\Lambda$ brahams, 1979; $\Lambda$ brahams et al., 1984a; Price and Dutia, 1987). Af ferents from other receptors, including Golgi tendon organs, do not fire tonically unless the muscle is subjected to large stretches. Thus, the presence of tonic activity is a simple means of identifying muscle spindle afferents. Furthermore, Richmond and Abrahams (1979) have found that most neck muscle afferents with a variability of instantaneous discharge frequency in excess of $4.5 \%$ have responses to ramp and hold stretches typical of primary endings of muscle spindles. The only other afferents with a variability of instantaneous frequency in this range have responses to ramp and hold stretches with "intermediate" characteristics

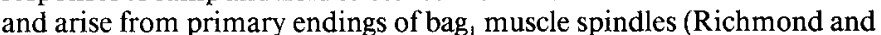
Abrahams, 1979; Richmond et al., 1986; Price and Dutia, 1987). The variability of instantaneous discharge frequency therefore provides a convenient means of distinguishing between primary and secondary endings that can be used in circumstances, such as the present experiments, where conventional stimuli (i.e., ramp and hold stretch) cannot be used. The variability of instantaneous discharge frequency was calculated by determining the maximum deviation of instantaneous discharge frequency from the mean discharge frequency and expressing it as a percentage of the mean frequency, as described by Richmond and Abrahams (1979). The afferents described in this study had mean instantaneous discharge frequencies of $18-63 \mathrm{spikes} / \mathrm{sec}$ and a variability of instantaneous discharge frequency of $6-46 \%$ of the mean.

HRP was iontophoretically injected into identified axons with 3-15 $\mathrm{nA}$ positive current pulses of $450 \mathrm{msec}$ duration, delivered at $2 \mathrm{~Hz}$ for 3-37 min. The membrane potential, which was monitored during the off-cycle, often deteriorated from -40 to $-60 \mathrm{mV}$ to -10 to $-20 \mathrm{mV}$ over the time course of the injection. The electrode was presumed to be intra-axonal as long as an action potential was evoked at the beginning of each depolarizing current pulse. Injection sites were separated by at least $2 \mathrm{~mm}$ to avoid extensive overlap of collaterals from different axons.

Histological methods. Three to fourteen hours after the first injection of HRP, 25,000 IU of heparin was administered intravenously, followed, several minutes later, by an overdose of sodium pentobarbital. Saline or dextran $(600 \mathrm{ml})$ was immediately perfused through the ascending aorta, followed by a $30 \mathrm{~min}$ infusion of $1.5-2.5$ liter of fixative consisting of $1.25 \%$ glutaraldehyde, $1 \%$ paraformaldehyde, and $0.2 \%$ dimethylsulfoxide in $0.1 \mathrm{~m}$ phosphate buffer $(\mathrm{pH}$ 7.3). The upper cervical spinal cord was excised and stored in fixative overnight at $2-4^{\circ} \mathrm{C}$. The spinal cord was cut into 1 - to 2 -cm-long blocks, which were then embedded in $7 \%$ agar. Serial, $75-\mu \mathrm{m}$-thick sections were cut in the sagittal 
plane using a vibratome (Oxford). The sections were collected in $0.1 \mathrm{M}$ phosphate buffer ( $\mathrm{pH} 7.3$ ), treated with cobalt chloride (Adams, 1977), and incubated for 30-90 min in either a solution of B-D-glucose, glucose oxidase, ammonium chloride, and diaminobenzidene tetrahydrochloride (DAB) in $0.1 \mathrm{M}$ phosphate buffer (Itoh et al., 1979) or a solution of DAB and hydrogen peroxide in $0.1 \mathrm{M}$ cacodylate buffer (Graham and Karnovsky, 1966).

Following incubation, sections were mounted on gelatine-coated slides and allowed to air dry overnight. The tissue was dehydrated in absolute alcohol, cleared in xylene, and coverslipped using a synthetic mounting medium (Permount, Fisher). Previous studies using these histological procedures have shown that tissue shrinkage does not exceed $6 \%$ (Rose, 1981), and therefore no correction was made for shrinkage.

Morphological analysis. Low-power drawings $(\times 125)$ were made of the parent axon in the dorsal funiculus using a $\times 10$ objective on a WildLeitz microscope equipped with a camera lucida drawing attachment. Intercollateral distances were obtained from these drawings using a cartographer's plan measure.

The collaterals of single afferents were reconstructed from 10-26 serial sections. All stained profiles on each section were drawn at a magnification of $\times 125$ using a $\times 10$ dry objective. With these low-power drawings as a guide, detailed drawings were made at a magnification of $\times 500$ using a $\times 40$ oil objective (NA 1.3). Points at which axonal profiles entered or left the section were color-coded so that the appropriate axonal profiles from adjacent sections could be matched to prevent loss of branches in the reconstruction process. The drawings of 3-5 sequential sections were combined to yield a composite drawing, of which there were 2-3 for each collateral. These composite drawings were traced onto transparent acetate film with ink, overlayed on a back-lit screen, and photographed with a large-format camera equipped with a long focal length lens (Sinar F $4 \times 5$ ) and high-contrast film (Kodalith ortho film, Type 3).

Using the criteria established by Conradi et al. (1983) in combined light and electron microscopic studies on hindlimb muscle afferent collaterals, swellings of the axon collaterals that exceeded the diameter of the adjacent axonal shaft more than 2 -fold were considered to be synaptic boutons. The distribution of boutons in the sagittal plane was determined from the sagittal reconstructions at $\times 500$. The distribution of boutons in the transverse plane was obtained by determining the dorsal-ventral position of each bouton using the gray-white borders visible in each of the sagittal sections as landmarks. The mediolateral position was determined by the section number and the depth at which each bouton was located within the section.

\section{Results}

\section{Branching pattern of axons in the dorsal funiculus}

The axons of 32 afferents (15 SP, 17 BCCM) were examined using low-power $(\times 125)$ reconstructions. These were stained for $1.3-15.0 \mathrm{~mm}$ along their course within a narrow region of the dorsal funiculus just medial to the dorsal roots (see also Abrahams et al., 1984b). Most afferents (18/20) that could be traced to their dorsal root entry bifurcated almost immediately upon entering the dorsal funiculus. One of these branches invariably ascended in the dorsal funiculus, while another branch descended in the dorsal funiculus (Fig. 1). The descending branch of 3 afferents turned ventrally and terminated as a collateral within the same segment in which the afferents entered the spinal cord (e.g., Fig. 1d). Although other descending branches could be traced to the caudal end of the segment in which the afferent entered the spinal cord (e.g., Fig. $1 j$ ), the HRP reaction product faded as the branches entered the next segment. In 2 cases the afferent turned rostrally to ascend in the dorsal funiculus and did not give rise to a descending branch (e.g., Fig. 1a).

Collaterals arose at irregular intervals from both the ascending and descending branches, and in one case, from the afferent before it branched (Fig. 1b). Adjaccnt collatcrals wcre scparated by distances that ranged from 0.56 to $5.60 \mathrm{~mm}$ (mean, 2.50 $\mathrm{mm}$ ). This may overestimate the frequency of collaterals, however, since 7 of the 32 afferents that were examined gave rise to one or no collaterals over lengths of $1.3-14.0 \mathrm{~mm}$ (e.g., Fig. $1 e$ ), and thus no measurement of intercollateral distance could be obtained. The average frequency of collaterals was therefore also calculated by dividing the combined lengths of all wellstained axons by the total number of collaterals observed. This calculation indicated that a collateral arose, on average, every $3.7 \mathrm{~mm}$ (80 collaterals over $293.83 \mathrm{~mm}$ of stained axon).

The calculated values of collateral frequency (total length of stained axon/number of collaterals) revealed differences between SP and BCCM afferents, as well as differences between afferents stained in segments rostral to their site of dorsal root entry versus those stained in the same segment as their dorsal root entry (Table 1 ). Afferents from $\mathrm{SP}$ gave rise to a collateral every $3.2 \mathrm{~mm}$, whereas collaterals arose from BCCM afferents every $4.4 \mathrm{~mm}$. This is a reflection of the fact that all 7 afferents that had fewer than 2 collaterals were from BCCM. In addition, the collateral frequency of afferents from all muscles was approximately twice as great on axons that were stained in the same segment as their site of dorsal root entry ( 1 collateral/3.3 $\mathrm{mm}$ ) than on those stained in more rostral segments ( 1 collateral $/ 6.3 \mathrm{~mm}$ ). This is partially because all 3 axons that did not give rise to any collaterals were stained 1-2 segments rostral to their site of dorsal root entry. Conversely, 18 of the 20 afferents that were stained near their site of dorsal root entry gave rise to 1-4 collaterals within $1 \mathrm{~mm}$ of the dorsal root entry (e.g., Fig. $1, a, b, d, g, i)$. In 12 of these 18 afferents, $1-3$ collaterals originated at the junction of the ascending and descending branches (e.g., Fig. 1, $d, g, j$ ). Although no major differences were observed between the calculated values of collateral frequency on ascending branches ( 1 collateral $/ 3.8 \mathrm{~mm}$ ) versus those on descending branches ( 1 collateral $/ 3.2 \mathrm{~mm}$ ) in the total population or in the population of SP afferents (1 collateral $/ 3.0 \mathrm{~mm}$ on ascending branches versus 1 collateral $/ 3.7 \mathrm{~mm}$ on descending branches), afferents from BCCM gave rise to collaterals approximately twice as often on descending branches ( 1 collateral/ $2.0 \mathrm{~mm})$ than on ascending branches $(1$ collateral $/ 4.8 \mathrm{~mm})$.

\section{Morphology of collaterals}

The branching structure and terminal distribution of 10 wellstained collaterals (5 SP, 5 BCCM) from 9 afferents were examined in detail. The arborizations of 2 additional BCCM collaterals were partially reconstructed at high powcr $(\times 500)$, whilc 4 other collaterals ( $2 \mathrm{SP}, 2 \mathrm{BCCM}$ ) that were faintly stained were reconstructed at low power $(\times 125)$. These low-power reconstructions were used only in a general analysis of distribution pattern.

The branching structure and terminal distribution of neck muscle afferent collaterals were generally similar regardless of the muscle from which the afferent originated. Consequently, the following description applies to all collaterals except where otherwise stated. From their origin on the parent axon, collaterals projected ventrally and, in some cases, rostrally through the dorsal funiculus (Figs. 2-5) and entered the gray matter via the medial border of the base of the dorsal horn. Along their course within the dorsal funiculus or within the intermediate zone of the gray matter, all collaterals divided into 2 or 3 large branches. Each of these large branches usually bi- or trifurcated within the medial part of the intermediate zone and gave rise to many fine terminal or preterminal branches that had boutons en passant and terminale (Fig. 6A). The dimensions of the boutons, which usually appeared ovoid and occasionally spherical, 


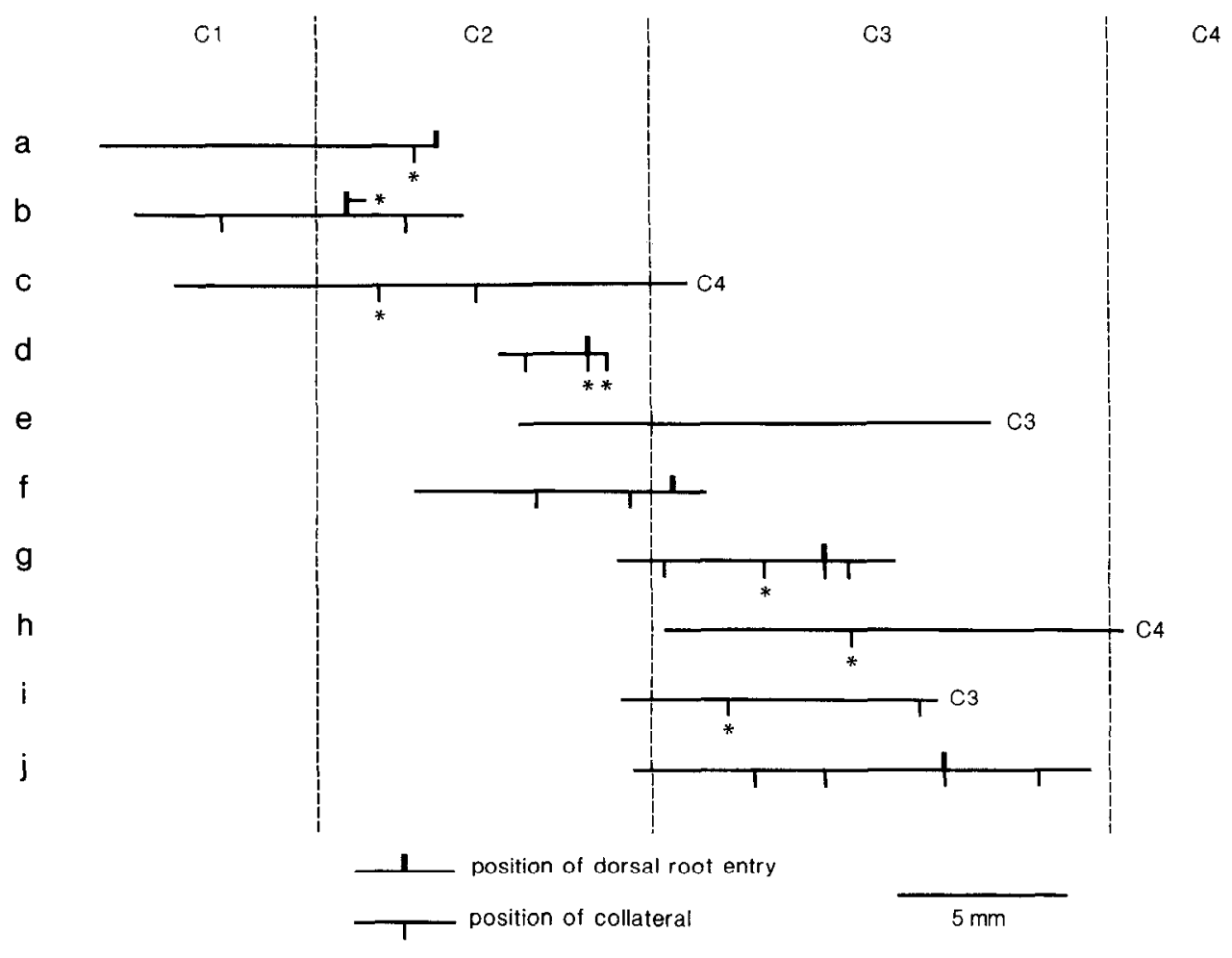

Figure 1. Examples of the branching structure of afferents in the dorsal funiculus. Each horizontal line represents the length of each stained axon; dashed lines delineate the borders between upper cervical spinal segments. The segment of dorsal entry is indicated to the right of each afferent whose site of dorsal root entry is not marked. The asterisks indicate the position of collaterals that have been completely reconstructed.

ranged from $1.2 \times 1.6 \mu \mathrm{m}$ to $2.4 \times 5.6 \mu \mathrm{m}$ (mean $\pm \mathrm{SD}, 2.0$ $\pm 0.7 \times 3.4 \pm 1.4 \mu \mathrm{m}, n=62$ ). The arborizations in this region formed a complex termination within and around the $\mathrm{CCN}$. Occasionally several branches with few boutons projected rostrally or caudally from this dense termination zone (Figs. 2 and 3). The average rostrocaudal extent of these projections was 970 $\mu \mathrm{m}$ (range, $380-2620 \mu \mathrm{m}$; Table 2 ), but the majority of boutons was confined to a smaller longitudinal zone, usually less than $700 \mu \mathrm{m}$ long. Because of their usually wide separation, adjacent collaterals were rarely well stained. However, 2 collaterals, 600 $\mu \mathrm{m}$ apart, from one axon were reconstructed (Fig. 1d). The termination zones of these collaterals in the area of the $\mathrm{CCN}$ did not overlap.

The termination zone in the CCN contained $87-658$ boutons and consisted of 34-86\% (average, $61 \%$ ) of the total number of boutons on a single collateral (Table 2). As Figures 7 and 8 illustrate, the majority of boutons in the intermediate zone were found in the medial half of this region, particularly within and around the CCN. Few boutons were found in more lateral parts of the intermediate zone and in the region just lateral to the central canal.

From the intermediate zone, 1-4 large branches of each collateral projected ventrally and ventrolaterally into the ventral horn. Many of the large branches projected rostrally, as well as ventrally, from the intermediate zone, so that the arborizations in the ventral horn were shifted slightly rostrally with respect to those in the intermediate zone. When more than one large collateral branch projected to the ventral horn, the terminal arborizations of the different branches overlapped. As they coursed from the intermediate zone, large-diameter branches gave rise to several fine terminal branches, which often projected rostrally or caudally from their origin on the parent branch. In addition, the larger branches often divided into 2-5 fine branches at a single node (Fig. $6 B$ ). At least one, and often several, of these branches projected ventrally to the ventral gray-white border, where they turned to run rostrally and caudally. Only rarely were branches or boutons found in the white matter. Most of the branches in the ventral horn projected for long distances,

\section{Table 1. Collateral frequency of afferents from dorsal neck muscles}

\begin{tabular}{|c|c|c|c|c|c|}
\hline Characteristic & $\begin{array}{l}\text { Ascending } \\
\text { branch }\end{array}$ & $\begin{array}{l}\text { Descending } \\
\text { branch }\end{array}$ & Same segment & Rostral segment & Overall \\
\hline \multicolumn{6}{|l|}{$\mathrm{SP}(n=15)$} \\
\hline Combined length of stained axon (mm) & 104.32 & 44.33 & 124.99 & 23.66 & 148.65 \\
\hline Number of collaterals & 35 & 12 & 43 & 4 & 47 \\
\hline Collateral frequency $(\mathrm{mm} /$ collateral) & 3.0 & 3.7 & 2.9 & 5.9 & 3.2 \\
\hline \multicolumn{6}{|l|}{$\operatorname{BCCM}(n=17)$} \\
\hline Combined length of stained axon (mm) & 135.12 & 10.06 & 99.36 & 45.82 & 145.18 \\
\hline Number of collaterals & 28 & 5 & 26 & 7 & 33 \\
\hline Collateral frequency (mm/collateral) & 4.8 & 2.0 & 3.8 & 6.5 & 4.4 \\
\hline
\end{tabular}

\footnotetext{
${ }^{a}$ All collaterals at the junction of the ascending and descending branch $(n=12)$ were assigned to the ascending branch (SP, $\left.n=7 ; \mathrm{BCCM}, n=5\right)$.
} 


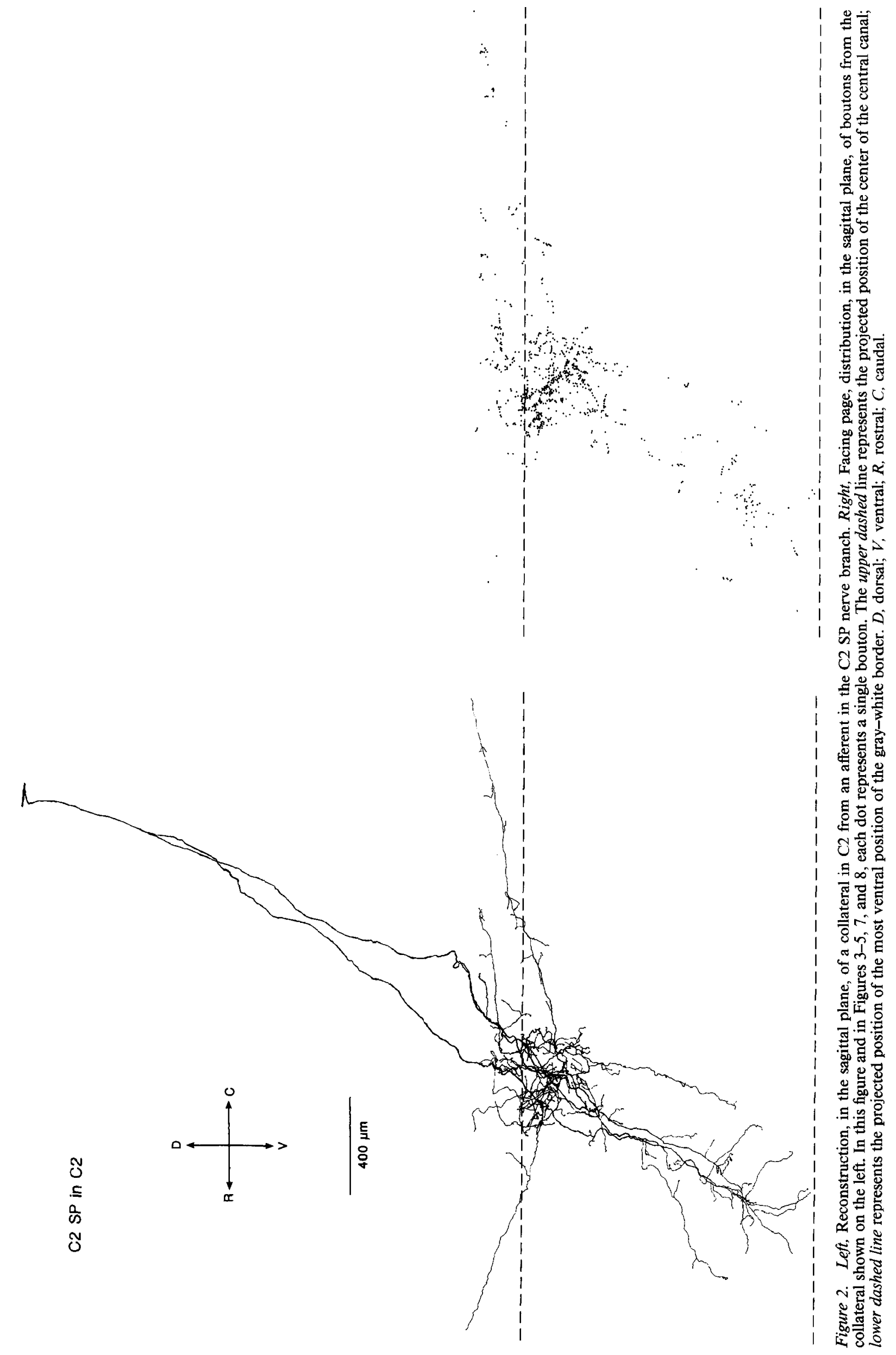




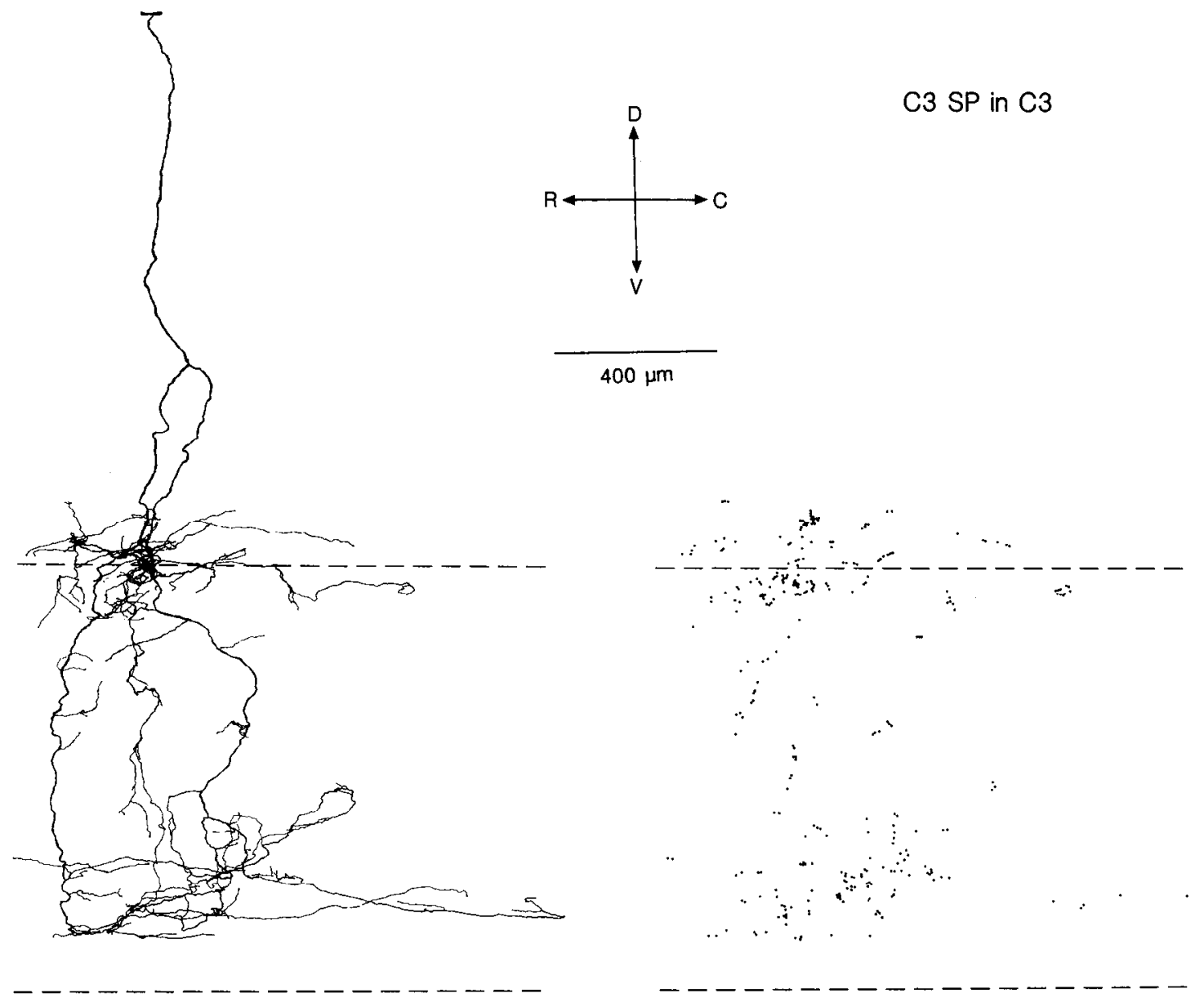

Figure 3. Left, Reconstruction, in the sagittal plane, of a collateral in C3 from an axon in the C3 SP nerve branch. Right, Distribution, in the sagittal plane, of boutons from the collateral shown on the left.

but, compared with branches in the intermediate zone, gave rise to fewer boutons along their course. The overall longitudinal extent of the arborizations in the ventral horn ranged from 260 to $2360 \mu \mathrm{m}$, with an average of $1035 \mu \mathrm{m}$. The ventral arbori-

Table 2. Quantitative characteristics of collaterals of afferents from dorsal neck muscles

\begin{tabular}{|c|c|c|c|c|}
\hline Collateral $^{a}$ & $\begin{array}{l}\text { Rostral- } \\
\text { caudal } \\
\text { extent in } \\
\text { inter- } \\
\text { mediate } \\
\text { zone } \\
(\mu \mathrm{m})\end{array}$ & $\begin{array}{l}\text { Number of } \\
\text { boutons in } \\
\text { intermed- } \\
\text { iate zone }\end{array}$ & $\begin{array}{l}\text { Rostral- } \\
\text { caudal } \\
\text { extent in } \\
\text { ventral } \\
\text { horn }(\mu \mathrm{m})\end{array}$ & $\begin{array}{l}\text { Number } \\
\text { of } \\
\text { boutons } \\
\text { in } \\
\text { ventral } \\
\text { horn }\end{array}$ \\
\hline $\mathrm{C} 2 \mathrm{SP}$ in $\mathrm{C} 2$ & 2620 & 658 & 840 & 104 \\
\hline $\mathrm{C} 3 \mathrm{SP}$ in $\mathrm{C} 3$ & 970 & 153 & 1300 & 143 \\
\hline $\mathrm{C} 2 \mathrm{BCCM}$ in $\mathrm{C} 2$ & 1880 & 277 & 1600 & 249 \\
\hline $\mathrm{C} 2 \mathrm{BCCM}$ in $\mathrm{C} 2$ & 620 & 197 & 2360 & 308 \\
\hline $\mathrm{C} 2 \mathrm{BCCM}$ in $\mathrm{C} 2$ & 750 & 163 & 1150 & 212 \\
\hline $\mathrm{C} 3 \mathrm{BCCM}$ in $\mathrm{C} 3$ & 380 & 279 & 1000 & 106 \\
\hline $\mathrm{C} 3 \mathrm{SP}$ in $\mathrm{C} 2$ & 490 & 188 & 700 & 64 \\
\hline $\mathrm{C} 3 \mathrm{SP}$ in $\mathrm{C} 2$ & 520 & 87 & 680 & 121 \\
\hline $\mathrm{C} 4 \mathrm{SP}$ in $\mathrm{C} 2$ & 500 & 142 & 260 & 55 \\
\hline $\mathrm{C} 4 \mathrm{BCCM}$ in $\mathrm{C} 3$ & 940 & 241 & 460 & 58 \\
\hline
\end{tabular}

${ }^{a}$ Each collateral is classified according to the segment in which its parent axon entered the spinal cord and the muscle innervated by the parent axon (i.e., $\mathrm{C} 2$ $\mathrm{SP})$. The segmental location of each collateral is also indicated (i.e., in C2). zation of the 2 adjacent collaterals described earlier shared a zone approximately $1000 \mu \mathrm{m}$ long. Despite the wider distribution of arborizations in the ventral horn, the number of boutons was comparable to that observed in the intermediate region (Table 2). The dimensions of boutons in the ventral horn were similar to those in the intermediate zone and ranged from 0.8 $\times 1.6 \mu \mathrm{m}$ to $2.0 \times 6.4 \mu \mathrm{m}($ mean $\pm \mathrm{SD}, 1.8 \pm 0.6 \times 2.9 \pm 1.0$ $\mu \mathrm{m})$.

The distribution of boutons in the ventral horn partially depended on the source of the afferent. Most collaterals from BCCM afferents terminated in the medial half of the ventral horn (Fig. 7), whcre dendrites of $\mathrm{BC}, \mathrm{CM}$, and SP motoneurons are found (Rose, 1981; Keirstead and Rose, 1983b). Some boutons of one of the 5 BCCM collaterals examined, however, were found more centrally and laterally. In cases where the ventral horn projection was extensive, the boutons were concentrated in the ventromedial nucleus, where many cell bodies of BC and CM motoneurons lie (Richmond et al., 1978; Rose, 1981; Abrahams and Keane, 1984). Although collaterals from SP afferents projected to these regions as well, their collaterals tended to have more branches that projected ventrolaterally from the CCN and to arborize in the central and/or lateral parts of the ventral horn (Fig. 8).

The complexity of the collateral arborizations in the ventral horn appeared to be related to the distance of the collateral from its segment of dorsal root entry. Collaterals in the same segment as their dorsal root entry gave rise to more complex networks 


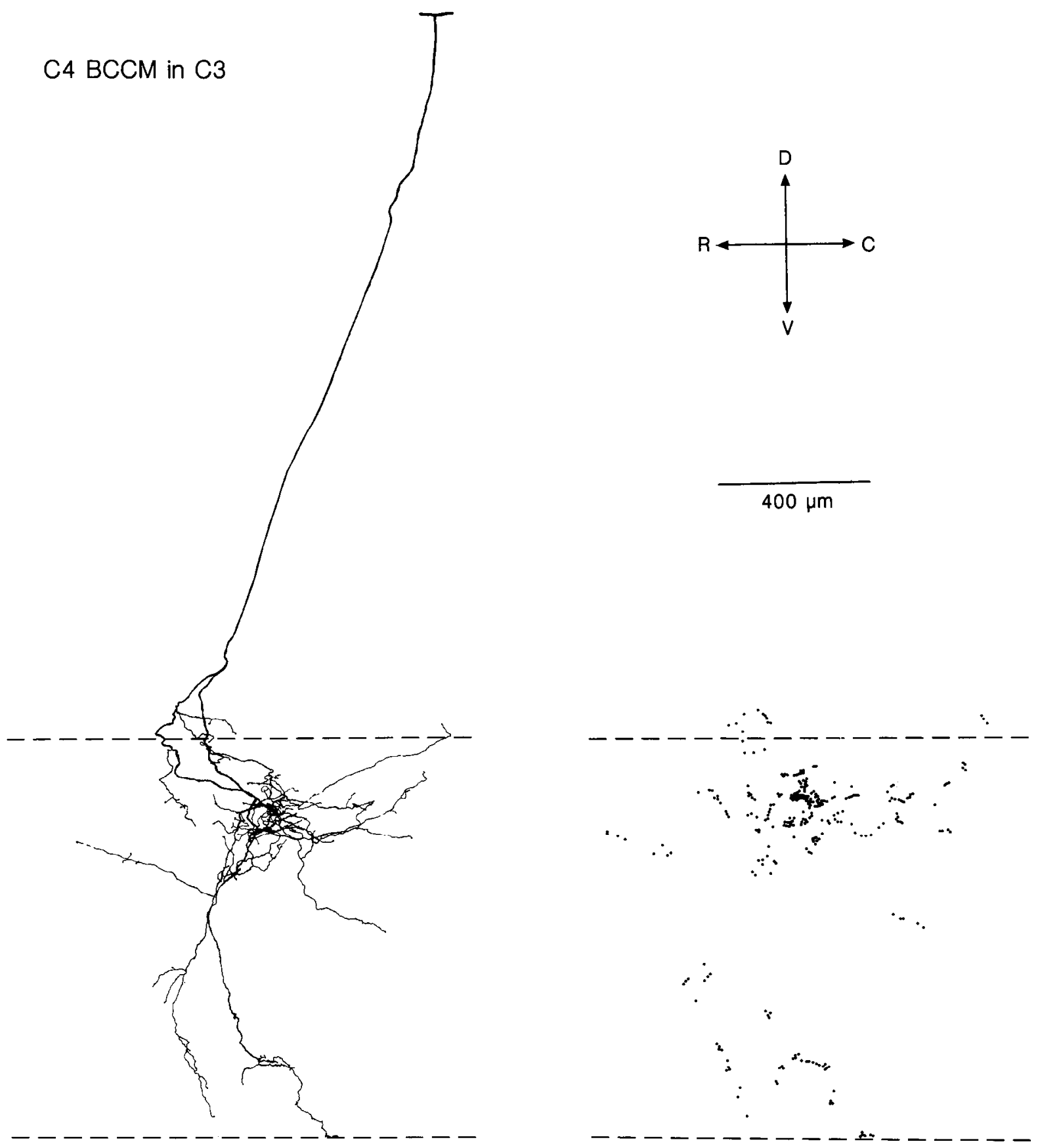

Figure 4. Left, Reconstruction, in the sagittal plane, of a collateral in C3 from an axon in the C4 BCCM nerve branch. Right, Distribution, in the sagittal plane, of boutons from the collateral shown on the left.

of fine terminal branches in the ventral horn than collaterals in more rostral segments (compare Figs. 2 and 3 to Figs. 4 and 5). Collaterals in the same segment as their dorsal root entry point had a significantly greater rostral-caudal extent in the ventral horn than collaterals in more rostral segments $(p=0.005$; MannWhitney $U$ test; see Table 2). Furthermore, the number of boutons in the ventral horn, as well as the total number of boutons per collateral, were both significantly greater on collaterals located in the same segment as their dorsal root entry than on collaterals in more rostral segments $(p=0.019$ and $p=0.01$ respectively; Mann-Whitney $U$ test).

\section{Discussion}

Organization of collaterals in the transverse plane

The results of this study, together with earlier observations of a smaller sample of neck muscle afferents (Hirai et al., 1984), indicate that afferents from primary endings of neck muscle spindles project to the intermediate zone of the gray matter, within and around the CCN, and to lamina VIII and IX. Slightly over half of the boutons of all of the collaterals examined were concentrated in the region of the CCN. Thus, at least some of the projections of neck muscle afferents to this region that have 


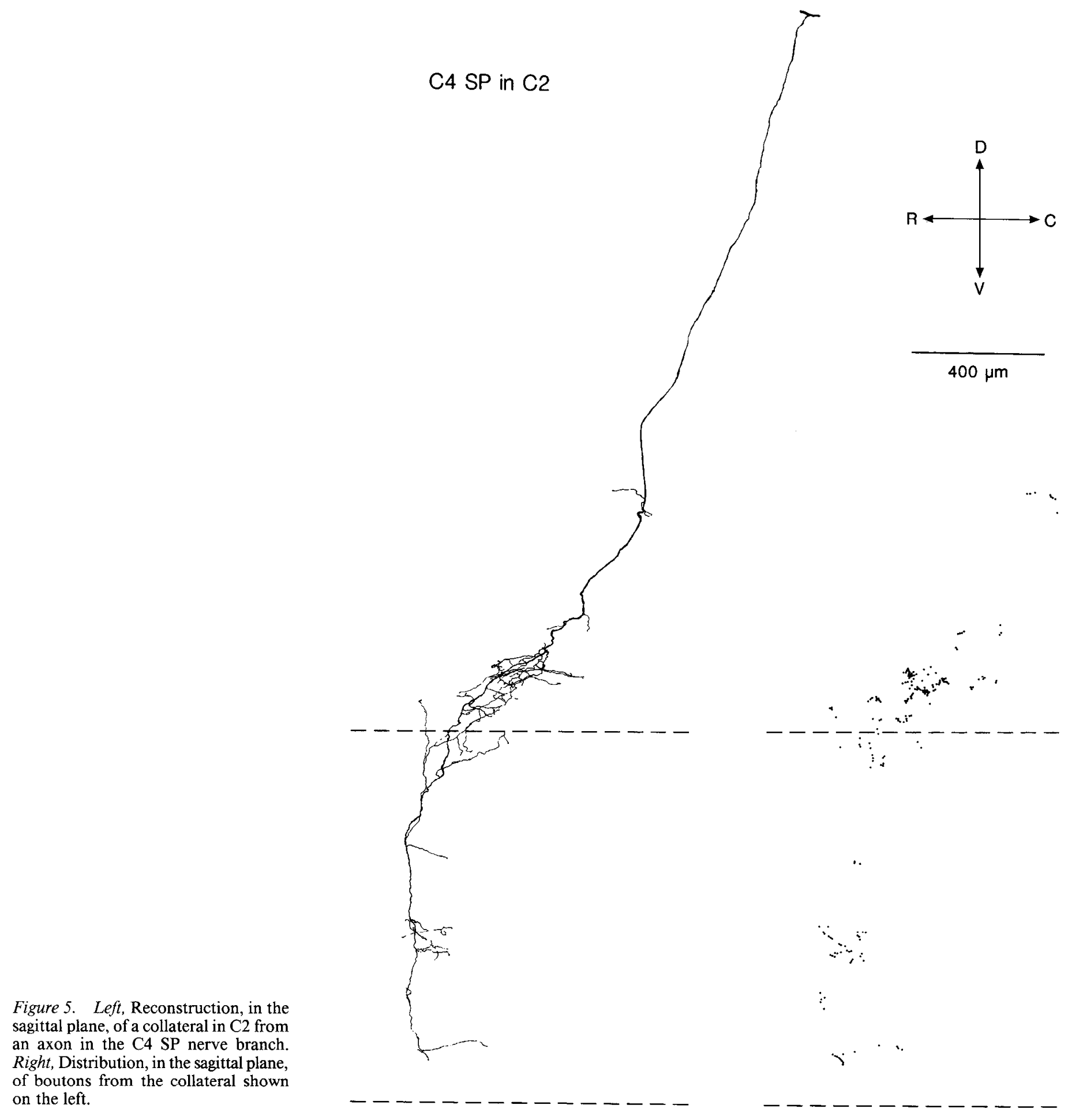

been demonstrated using transganglionic transport of HRP (Abrahams et al., 1984b; Nyberg and Blomqvist, 1984) originate from afferents which innervate primary endings of neck muscle spindles.

Although elements postsynaptic to stained axons could not be identified in the present studies, the distribution of boutons in the region of the CCN and ventral horn is consistent with the results of electrophysiological studies in which monosynaptic EPSPs were evoked in spinocercbcllar tract neurons in CCN (Hirai et al., 1984) and motoneurons innervating SP, BC, and
CM (Wilson and Maeda, 1974; Anderson, 1977; Brink et al., 1981). The electrophysiological studies also demonstrated that afferents from SP and BCCM rarely converge on the same spinocerebellar tract neurons in $\mathrm{CCN}$ or dorsal neck motoneurons. Yet it is apparent from the present study that the terminal arborizations of collaterals from SP afferents overlap extensively with those of BCCM afferents, both in the CCN and the ventral horn. This type of specific connectivity, in spite of anatomical overlap, has becn obscrved in other regions of the spinal cord, including the brachial spinal cord of the bullfrog (Lichtman and 

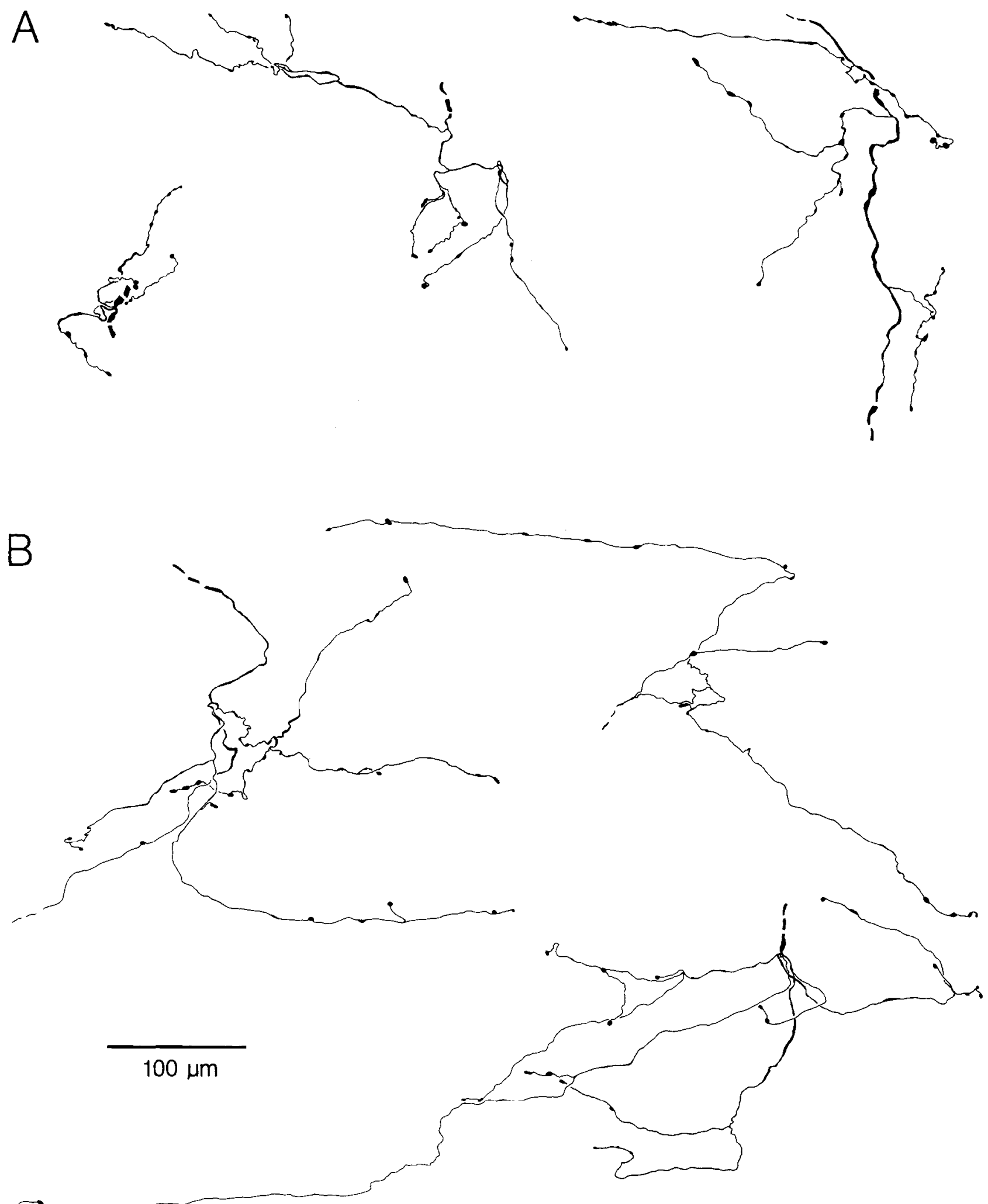

Figure 6. High-power drawings of preterminal and terminal branches of collaterals terminating in the intermediate zone $(A)$ and in the ventral horn $(B)$.

Frank, 1984; Lichtman et al., 1984) and the lumbosacral spinal cord of the cat (Scott and Mendell, 1976; Ishizuka et al., 1979).

If our morphological data are compared with similar data on afferents supplying hindlimb muscle spindle primary endings
(Brown and Fyffe, 1978; Ishizuka et al., 1979), it becomes clear that the ventral horn projections of hindlimb muscle afferents are more extensive than those of neck muscle spindle afferents (Fig. 9). Based on the average intercollateral distance $(1 \mathrm{~mm})$ 


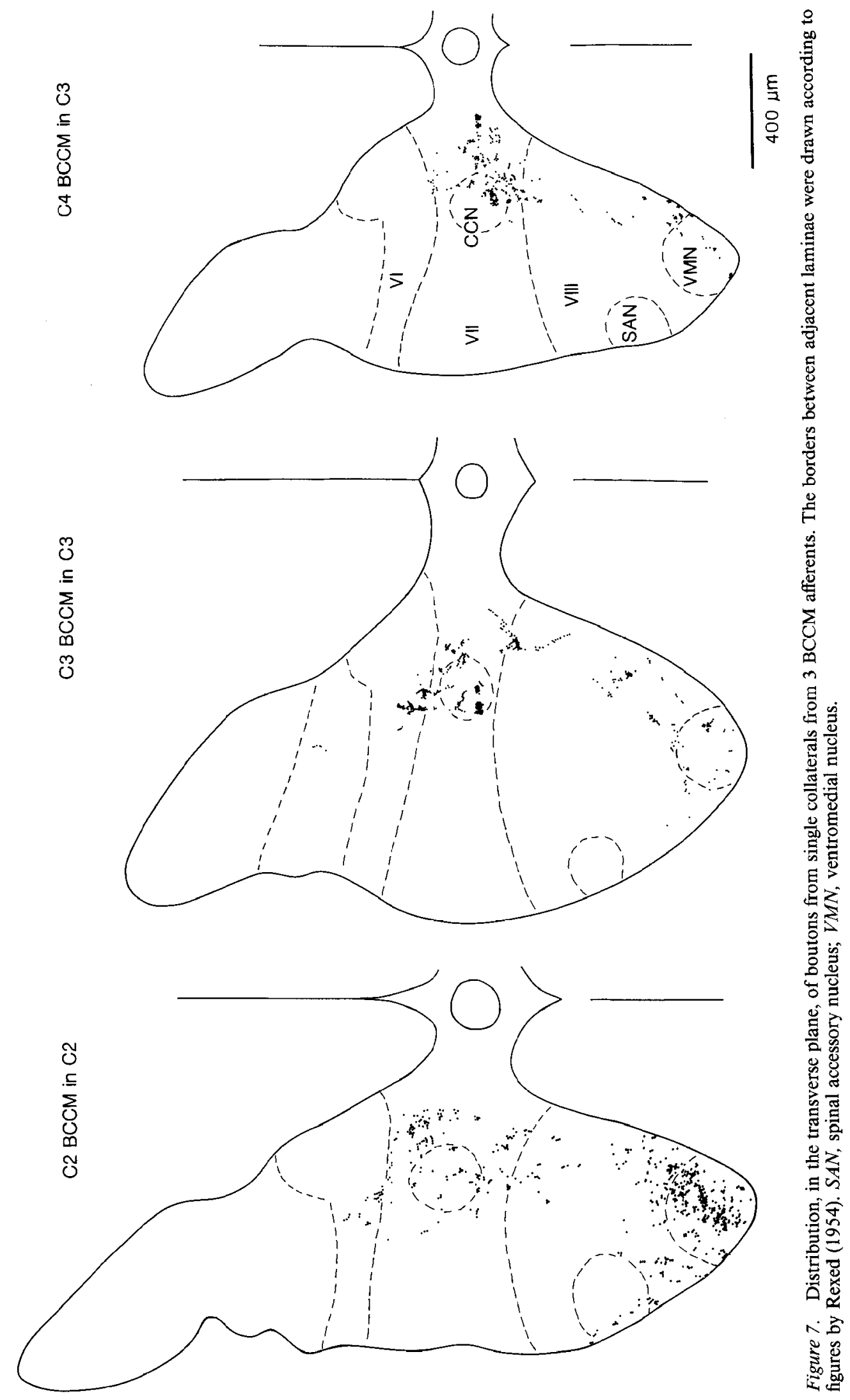




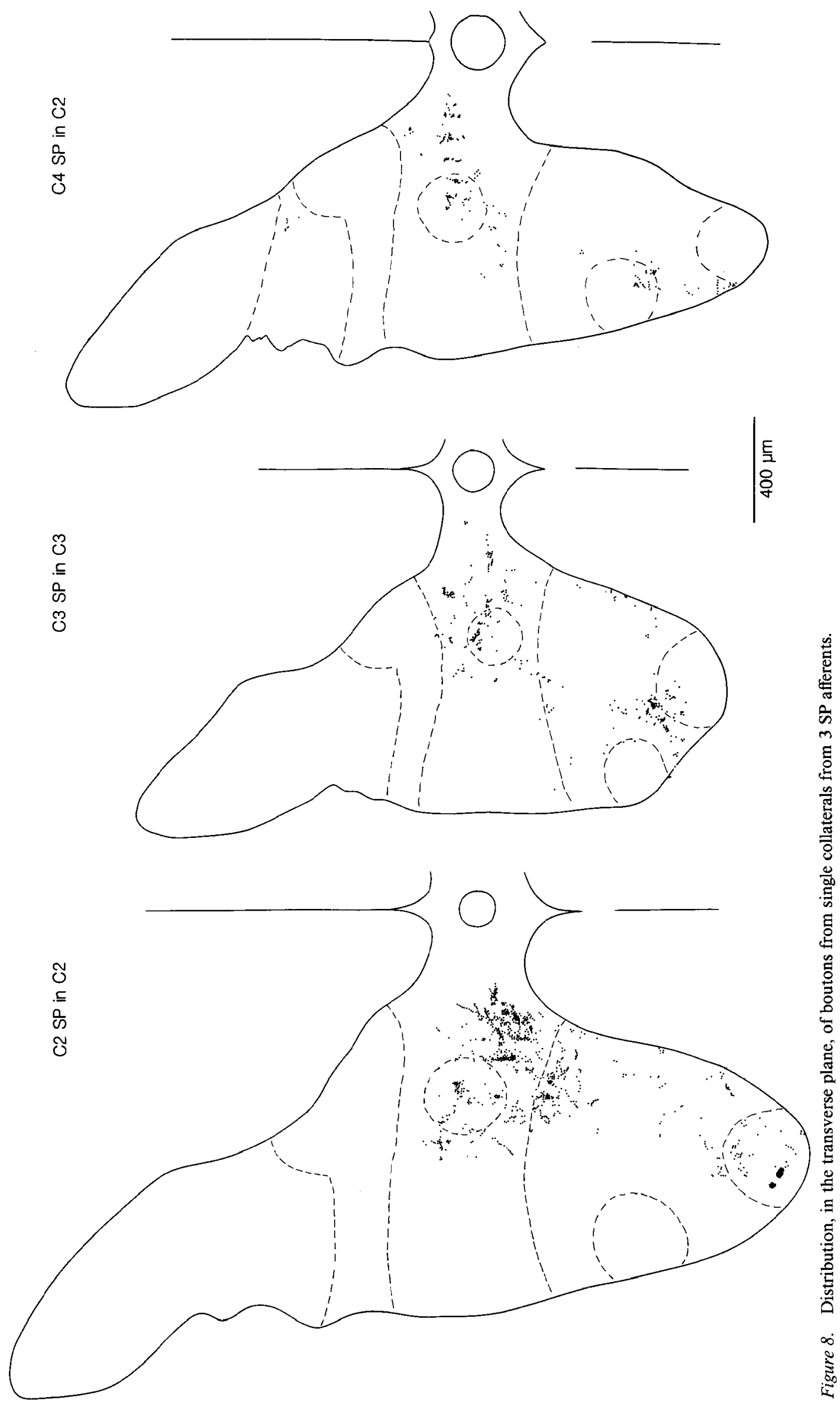




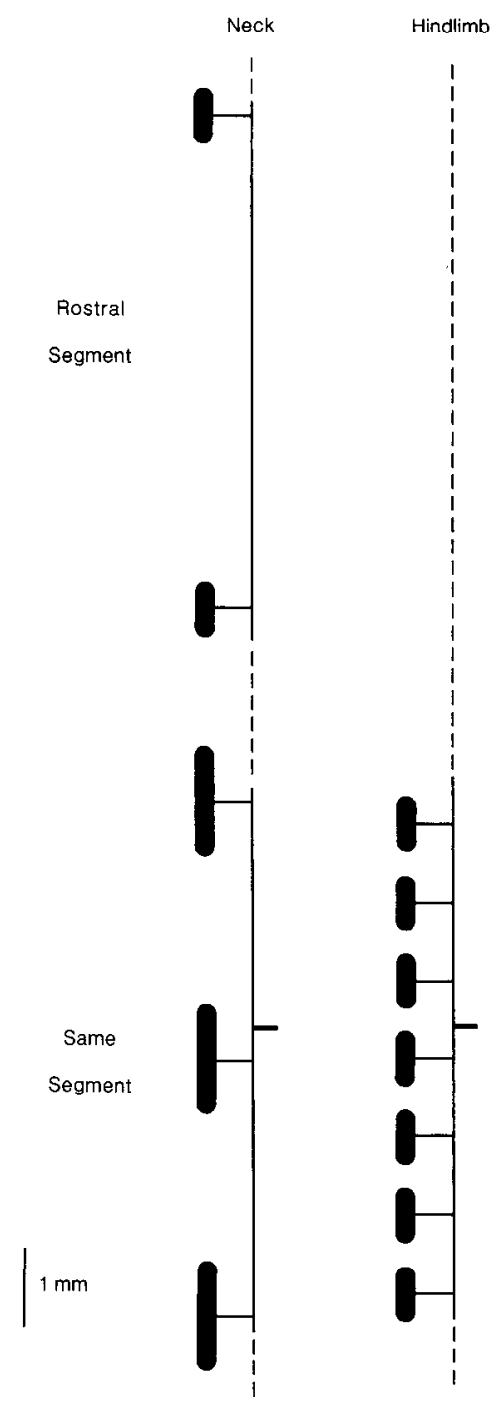

Figure 9. Schematic diagrams comparing the ventral horn projections of afferents innervating primary endings of muscle spindles from neck and hindlimb muscles. The dashed lines at the rostral and caudal poles of the axons indicate the projection of axons in zones where there is little, if any, information on the characteristics of projections to the ventral horn. The projections for neck muscle afferents are shown for axons travelling in the same segment as the dorsal root entry point as well as axons travelling in segments rostral to their dorsal root entry point. The distance between adjacent collaterals and the longitudinal extent of branches of individual collaterals, indicated by the black zones, are based on average measurements. The data for constructing the schematic representation of the hindlimb axon is based on the experiments of Brown and Fyffe (1978) and Ishizuka et al. (1979).

and number of boutons per collateral (136 boutons/collateral), the average density of boutons from hindlimb muscle afferents in the ventral horn is 136 boutons $/ \mathrm{mm}$. This density is considerably greater than the richest projection of neck muscle afferents, which is 61 boutons $/ \mathrm{mm}$ ( 1 collateral $/ 3.3 \mathrm{~mm} ; 200$ boutons/collateral) in the same segment as the afferents' dorsal root entry. Although this difference might explain the small amplitude of monosynaptic EPSPs that have been recorded in neck motoneurons (Rapoport, 1979; Brink et al., 1981) compared with those observed in hindlimb motoneurons (Eccles et al., 1957), other factors, such as a higher density of motoneurons or a smaller number of active zones per bouton, could also lead to smaller monosynaptic EPSPs in neck motoneurons.
While most of the electrophysiological studies describing the potential targets of muscle spindle afferents of dorsal neck muscles have been concerned with connections to spinocerebellar tract neurons and motoneurons, the connections of these afferents need not be restricted to these cells. Several other types of neurons have been identified in the upper cervical spinal cord which lie in the same region as the zones occupied by boutons of afferents from primary endings of neck muscle spindles. Some of the neurons project to the dorsal column nuclei (Rustioni and Kaufman, 1977); to the inferior olivary complex (BuisseretDelmas, 1980; Richmond et al., 1982); to the thalamus (Carstens and Trevino, 1978; Comas and Snow, 1981); to the reticular formation (Corvaja et al., 1977; Elisevich et al., 1985); to the cerebellum, from neurons outside the CCN (Matsushita et al., 1979a; Matsushita and Hosoya, 1982); and to caudal spinal segments (Molenaar and Kuypers, 1978; Matsushita et al., 1979b; Grant et al., 1980). Indeed, it has recently been reported that some short $\mathrm{C} 3-\mathrm{C} 4$ and long $\mathrm{C} 3-\mathrm{C} 5$ propriospinal neurons are monosynaptically excited by neck afferents that enter in the $\mathrm{C} 2$ dorsal root (Illert et al., 1978; Alstermark et al., 1987). Except for short C3-C4 propriospinal neurons that apparently do not receive direct connections from dorsal neck muscle afferents, the possibility of monosynaptic connections between dorsal neck muscle afferents and neurons other than motoneurons and neurons in $\mathrm{CCN}$ has not been explored.

\section{Organization of collaterals in the longitudinal plane}

Some afferents either did not project caudally from their site of dorsal root entry, or the descending branch turned ventrally before reaching the caudal end of the segment in which the afferent entered the spinal cord and terminated as a collateral. These findings are consistent with the observations of Brink et al. (1981), who reported that low-intensity stimulation of dorsal neck muscle afferents from SP did not evoke EPSPs in segments caudal to the entry of the excited afferents. It should be emphasized, however, that other axons likely continued into the segment caudal to their segment of dorsal root entry. Since staining intensity of intra-axonally labeled axons decreases with distance from the injection site, it was impossible to trace these axons to their caudal destination. Thus, it is possible that a significant proportion of muscle afferents from dorsal neck muscles do have long caudal projections. These afferents may contribute to the short-latency responses recorded in spinocerebellar neurons in $\mathrm{CCN}$ following stimulation of muscle nerves that lay 1-2 segments rostral to the location of the spinocerebellar neurons (Hirai et al., 1984). This characteristic of dorsal neck muscle afferents may be a feature of afferents from other neck muscles as Suzuki et al. (1986) has recently reported monosynaptic connections from perivertebral neck muscle afferents in the $\mathrm{C} 2$ ganglion to neurons in $\mathrm{C} 4$.

It is clear from our studies, as well as from recent electrophysiological studies (Brink et al., 1981; Hirai et al., 1984), that the principal focus of neck muscle afferent projections is in the segment at which the afferent enters the spinal cord. Collaterals were seen more frequently in the same segment as the afferent's dorsal root entry, than in other, more rostral segments (Fig. 9). The results of Hirai et al. (1984) are consistent with these observations, and perhaps are a direct consequence of this arrangement. These authors reported that stimulation of lowthreshold muscle afferents evoked monosynaptic excitatory responses more frequently in spinocerebellar neurons in the $\mathrm{CCN}$ that were in the same segment in which the afferents en- 
tered the spinal cord than in spinocercbellar ncurons that were in the CCN in other segments.

The importance of segmental location was most notable with respect to the ventral horn projections (Fig. 9). Collaterals that were in the same segment as the afferent's dorsal root entry had more complex arborizations in the ventral horn, spread farther in the longitudinal plane, and had more boutons than collaterals that were in more rostral segments. This, together with the higher incidence of collaterals, results in denser muscle spindle afferent projections within the segment of the afferent's dorsal root entry. Because of a lower frequency of collaterals (1/6.3 mm vs. 1/3.3 $\mathrm{mm}$ ) and fewer boutons/collateral ( $75 \mathrm{vs.} 200)$, the average density of boutons is only 12 boutons $/ \mathrm{mm}$ in segments rostral to the afferent's dorsal root entry, compared with 61 boutons $/ \mathrm{mm}$ in the same segment as the afferent entered the spinal cord. These estimates may explain the observations of Brink et al. (1981), who reported that low-intensity stimulation of individual branches of neck muscle nerves evoked larger EPSPs in motoneurons in the same segment as the dorsal root entry of the afferents than did stimulation of caudal nerve branches.

Approximately $80 \%$ of the axons we examined gave rise to at least one collateral within $1 \mathrm{~mm}$ of the dorsal root entry point. This suggests that connections may also be selectively arranged within the segment of dorsal root entry, such that those neurons closest to the site of dorsal root entry are most likely to be contacted. There is electrophysiological evidence that this type of preferential distribution of Ia effects exists in the lumbosacral spinal cord (Luscher et al., 1984), but this possibility has not been examined systematically in the upper cervical spinal cord.

\section{References}

Abrahams, V. C., and J. Keane (1984) Contralateral, midline, and commissural motoneurons of neck muscles: A retrograde HRP study in the cat. J. Comp. Neurol. 223: 448-456.

Abrahams, V. C., F. Richmond, and P. K. Rose (1975) Absence of monosynaptic reflex in dorsal neck muscles of the cat. Brain Res. 92: 130-131.

Abrahams, V. C., G. Anstee, F. J. R. Richmond, and P. K. Rose (1979) Neck muscle and trigeminal input to the upper cervical cord and lower medulla of the cat. Can. J. Physiol. Pharmacol. 57: 642-651.

Abrahams, V. C., B. Lynn, and F. J. K. Richmond (1984a) Organization and sensory properties of small myelinated fibres in the dorsal cervical rami of the cat. J. Physiol. (Lond.) 347: 177-187.

Abrahams, V. C., F. J. R. Richmond, and J. M. Keane (1984b) Projections of $\mathrm{C} 2$ and $\mathrm{C} 3$ nerves supplying muscles and skin of the cat neck. A study using transganglionic transport of horseradish peroxidase. J. Comp. Neurol. 230: 142-154.

Adams, J. C. (1977) Technical considerations on the use of HRP as a neuronal marker. Neuroscicnec 2: 141-145.

Alstermark, B., A. Lundberg, M. Pinter, and S. Sasaki (1987) Long $\mathrm{C}_{3}-\mathrm{C}_{5}$ propriospinal neurones in the cat. Brain Res. 404: 382-388.

Ammann, B., J. Gottschall, and W. Zenker (1983) Afferent projections from rat longus capitis muscle studied by transganglionic transport of HRP. Anat. Embryol. 166: 275-289.

Anderson, M. E. (1977) Segmental reflex inputs to motoneurons innervating dorsal neck musculature in the cat. Exp. Brain Res. 28: 175-187.

Bakker, D. A., F. J. R. Richmond, and V. C. Abrahams (1984) Central projections from cat suboccipital muscles: A study using transganglionic transport of horseradish peroxidase. J. Comp. Neurol. 228: 409-421.

Botterman, B. R., T. M. Hamm, R. M. Reinking, and D. G. Stuart (1983a) Localization of monosynaptic Ia excitatory postsynaptic potentials in the motor nucleus of cat biceps femoris muscle. J. Physiol. (I ond.) 338: 355-377

Botterman, B. R., T. M. Hamm, R. M. Reinking, and D. G. Stuart (1983b) Distribution of monosynaptic Ia excitatory postsynaptic po- tentials in the motor nucleus of the cat semitendinous muscle. J. Physiol. (Lond.) 330: 379-393.

Brink, E. E., K. Jinnai, and V. J. Wilson (1981) Pattern of segmental monosynaptic input to cat dorsal neck motoneurons. J. Neurophysiol. 46: 496-505.

Brown, A. G., and R. E. W. Fyffe (1978) The morphology of group Ia afterent fibre collaterals in the spinal cord of the cat. J. Physiol. (Lond.) 274: 111-127.

Brown, A. G., and R. E. W. Fyffe (1979) The morphology of group $\mathrm{Ib}$ afferent fibre collaterals in the spinal cord of the cat. J. Physiol. (Lond.) 296: 21 5-228.

Ruisseret-Delmas, C. (1980) An HRP study of the afferents to the inferior olive in cat. I. Cervical spinal and dorsal column nuclei projections. Arch. Ital. Biol. 118: 270-286.

Carli, G., K. Diete-Spiff, and O. Pompeiano (1967) Mechanisms of muscle spindle excitation. Arch. Ital. Biol. 105: 273-289.

Carstens, E., and D. L. Trevino (1978) Laminar origins of spinothalamic projections in the cat as determined by the retrograde transport of horseradish peroxidase. J. Comp. Neurol. 182: 151-166.

Chan, Y. S., J. Kasper, and V. J. Wilson (1987) Dynamics and directional sensitivity of neck muscle spindle responses to head rotation. J. Neurophysiol. 57: 1716-1729.

Comas, P. E., and P. J. Snow (1981) Rostrocaudal and laminar distribution of spinothalamic neurons in the high cervical spinal cord of the cat. Brain Res. 223: 123-127.

Conradi, S., S. Cullheim, I.. Gollvik, and J. O. Kellerth (1983) Electron microscopic observations on the synaptic contacts of group Ia muscle spindle afferents in the cat lumbosacral spinal cord. Brain Res. 265: 31-39.

Corbin, K. B., W. T. Lhamon, and D. W. Petit (1937) Peripheral and central connections of the upper cervical dorsal root ganglia in the rhesus monkey. J. Comp. Neurol. 66: 405-414.

Corvaja, N., I. Grofova, O. Pompeiano, and F. Walberg (1977) The lateral reticular nucleus in the cat. I. An experimental anatomical study of its spinal and supraspinal afferent connections. Neuroscience 2: $537-553$.

Deschenes, M., A. Labelle, and P. Landry (1979) Morphological characterization of slow and fast pyramidal tract cells in the cat. Brain Res. 178: 251-274.

Fccles, J. C., R. M. Fccles, and A. I undiberg (1957) The convergence of monosynaptic excitatory afferents on to many different species of alpha motoneurons. J. Physiol. (Lond.) 137: 22-50.

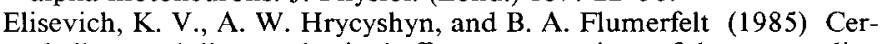
ebellar, medullary and spinal afferent connections of the paramedian reticular nucleus in the cat. Brain Res. 332: 267-282.

Escolar, J. (1948) The afferent connections of the 1st, 2nd and 3rd cervical nerves in the cat. J. Comp. Neurol. 89: 79-92.

Ezure, K., S. Sasaki, Y. Uchino, and V. J. Wilson (1978) Frequencyresponse analysis of vestibular-induced neck reflex in cat. II. Functional significance of cervical afferents and polysynaptic descending pathways. J. Neurophysiol. 41: 459-471.

Fyffe, R. E. W., S. S. Cheema, and A. Rustioni (1986) Intracellular staining study of the feline cuneate nucleus. I. Terminal patterns of primary afferent fibers. J. Neurophysiol. 56: 1268-1283.

Graham, R. C., Jr., and M. J. Karnovsky (1966) The early stages of absorption of injected horseradish peroxidase in the proximal tubules of mouse kidney: Ultrastructural cylochemistry by a new technique. J. Histochem. Cytochem. 14: 291-302.

Grant, G., M. Illert, and R. Tanaka (1980) Integration in descending motor pathways controlling the forelimb in the cat. 6 . Anatomical evidence consistent with the existence of $\mathrm{C} 3-\mathrm{C} 4$ propriospinal neurones projecting to forelimb motor nuclei. Exp. Brain Res. 38: 8793.

Hamm, T. M., W. Koehler, D. G. Stuart, and S. Vanden Noven (1986) Partitioning of monosynaptic Ia excitatory postsynaptic potentials in the motor nucleus of the cat semimembranous muscle. J. Physiol. (Lond.) 369: 379-398.

Hirai, N., T. Hongo, and S. Sasaki (1978) Cerebellar projection and input organizations of the spinocerebellar tract arising from the central cervical nucleus in the cat. Brain Res. 157: 341-345.

Hirai, N., T. Hongo, S. Sasaki, M. Yamashita, and K. Yoshida (1984) Neck muscle afferent input to spinocerebellar tract cells of the central cervical nucleus in the cat. Exp. Brain Res. 55: 286-300.

Hongo, T., N. Kudo, S. Sasaki, M. Yamashita, K. Yoshida, N. Ishizuka, and H. Manner (1987) Trajectory of group Ia and Ib fibers from 
the hindlimb muscles at the L3-L4 segments of the spinal cord of the cat. J. Comp. Neurol. 262: 159-194.

Illert, M., A. Lundberg, Y. Padel, and R. Tanaka (1978) Integration in descending motor pathways controlling the forclimb in the cat. 5 . Properties of and monosynaptic excitatory convergence on C3-C4 propriospinal neurones. Exp. Brain Res. 33: 101-130.

Imai, Y. (1964) Intraspinal distributions of the dorsal root fibers in cats. Recent Adv. Res. Nerv. Syst. 8: 695-716.

Imai, Y., and T. Kusama (1969) Distribution of the dorsal root fibres in the cat. An experimental study with the nauta method. Brain Res. 13: $338-359$.

Ishizuka, N., H. Mannen, T. Hongo, and S. Sasaki (1979) Trajectory of group Ia afferent fibers stained with horseradish peroxidase in the lumbosacral spinal cord of the cat: Three dimensional reconstructions from serial sections. J. Comp. Neurol. 186: 189-212.

Itoh, K., A. Konishi, S. Nomura, N. Mizuno, Y. Nakamura, and T. Sugimoto (1979) Application of coupled oxidation reaction to electron microscopic demonstration of horseradish peroxidase: Cobaltglucose oxidase method (cGOD). Brain Res. 175: 341-346.

Keirstead, S. A., and P. K. Rose (1983a) Projections of neck muscle spindle afferents intra-axonally stained with horseradish peroxidase in the upper cervical spinal cord of the cat. Soc. Neurosci. Abstr. 9: 663.

Keirstead, S. A., and P. K. Rose (1983b) Dendritic distribution of splenius motoneurons in the cat: Comparison of motoneurons innervating different regions of the muscle. J. Comp. Neurol. 219: 273284.

Keirstead, S. A., and P. K. Rose (1984) An examination of muscle spindle afferent motoneuron connectivity in the upper cervical spinal cord. Can. J. Physiol. Pharmacol. 62: AXVII.

Lichtman, J. W., and E. Frank (1984) Physiological evidence for specificity of synaptic connections between individual sensory and motor neurons in the brachial spinal cord of the bull frog. J. Neurosci. 4 : $1745-1753$

Lichtman, J. W., S. Jhaveri, and E. Frank (1984) Anatomical basis of specific connections between sensory axons and motor neurons in the brachial spinal cord of the bull frog. J. Nuerosci. 4: 1754-1763.

Lucas, S. M., and M. D. Binder (1984) Topographical factors in distribution of homonymous group Ia-afferent input to cat medial gastronemius motoneurons. J. Neurophysiol. 51: 50-63.

Luscher, H.-R., J. Mathis, and E. Henneman (1984) Wiring diagrams of functional connectivity in monosynaptic reflex arcs of the spinal cord. Neurosci. Lett. 45:217-222.

Matsushita, M., and Y. Hosoya (1982) Spinocerebellar projections to lobules III to $\mathrm{V}$ of the anterior lobe in the cat, as studied by retrograde transport of horseradish peroxidase. J. Comp. Ncurol. 9: 127-143.

Matsushita, M., Y. Hosoya, and M. Ikeda (1979a) Anatomical organization of the spinocerebellar system in the cat, as studied by retrograde transport of horseradish peroxidase. J. Comp. Neurol. 184:81106.

Matsushita, M., M. Ikeda, and Y. Hosoya (1979b) The location of spinal neurons with long descending axons (long descending propriospinal tract neurons) in the cat: A study with the horseradish peroxidase technique. J. Comp. Neurol. 184: 63-80.

Matthews, P. B. C. (1972) Mammalian Muscle Receptors and Their Central Actions. Arnold, London.

Matthews, P. R. C., and R. B. Stein (1969) The regularity of primary and secondary muscle spindle afferent discharges. J. Physiol. (Lond.) 202: 59-82.

Molenaar, I., and H. J. M. Kuypers (1978) Cells of origin of propriospinal fibres and of fibres ascending to supraspinal levels. A HRP study in cat and rhesus monkey. Brain Res. 152: 429-450.

Nyberg, G., and A. Blomqvist (1984) The central projection of muscle afferent fibres to the lower medulla and upper spinal cord. An anatomical study in the cat with the transganglionic transport method. J. Comp. Neurol. 230: 99-109.

Price, R. F., and M. B. Dutia (1987) Properties of cat neck muscle spindles and their excitation by succinycholine. Exp. Brain Res. 68 $619-630$.
Ranson, S. W., H. K. Davenport, and E. A. Doles (1932) Intramedullary course of the dorsal root fibers of the first three cervical nerves. J. Comp. Neurol. 54: 1-12.

Rapoport, S. R. (1979) Reflex connexions of motoneurones of muscles involved in head movement in the cat. J. Physiol. (Lond.) 289: 311327.

Rexed, B. (1954) A cytoarchitectonic atlas of the spinal cord in the cat. J. Comp. Neurol. 100: 297-351.

Richmond, F. J. R., and V. C. Abrahams (1975) Morphology and distribution of muscle spindles in dorsal muscles of the cat neck. $J$. Neurophysiol. 38: 1322-1339.

Richmond, F. J. R., and V. C Abrahams (1979) Physiological properties of muscle spindles in dorsal neck muscles of the cat. J. Neurophysiol. 42: 604-617.

Richmond, F. J. R., D. A Scott, and V. C. Abrahams (1978) Distribution of motoneurones to the neck muscles, biventer cervicis, splenius and complexus in the cat. J. Comp. Neurol. 181: 451-464.

Richmond, F. J. R., J. Courville, and J. A. Saint-Cyr (1982) Spinoolivary projections from the upper cervical spinal cord: An experimental study using autoradiography and horseradish peroxidase. Exp. Brain Res. 47: 239-251.

Richmond, F. J. R., G. J. Bakker, D. A. Bakker, and M. J. Stacey (1986) The innervation of tandem muscle spindles in the cat neck. J. Comp. Neurol. 245: 483-497.

Rose, P. K. (1981) Distribution of dendrites from biventer cervicis and complexus motoneurons stained intracellularly with horseradish peroxidase in the adult cat. J. Comp. Neurol. 197: 395-409.

Rose, P. K., and S. A. Keirstead (1986) Segmental projection from muscle spindles: A perspective from the upper cervical spinal cord. Can. J. Physiol. Pharmacol. 64: 505-508.

Rustioni, A., and A. B. Kaufman (1977) Identification of cells of origin of non-primary afferents to the dorsal column nuclei of the cat. Exp. Brain Res. 27: 1-14

Scott, J. G., and L. M. Mendell (1976) Individual EPSPs produced by single triceps surae Ia afferent fibres in homonymous and heteronymous motoneurons. J. Neurophysiol. 39: 679-692.

Shriver, J. E., B. M. Stein, and M. B. Carpenter (1968) Central projections of spinal dorsal roots in the monkey. I. Cervical and upper thoracic dorsal roots. Am. J. Anat. 123: 27-74.

Snow, P. J., A. G. Brown, and P. K. Rose (1976) Tracing axons and axon collaterals of spinal neurons using intracellular injection of horseradish peroxidase. Sci. 191: 312-313.

Suzuki, I., B. R. Park, and V. J. Wilson (1986) Direction sensitivity of, and neck afferent input to, cervical and lumbar interneurons modulated by neck rotation. Brain Res. 367: 356-359.

Szentagothai, J. (1948) Anatomical considerations of monosynaptic reflex arcs. J. Neurophysiol. 11: 445-454.

Takahashi, O., Y. Takeuchi, and R. Matsushima (1985) Direct connections of primary afferent fibers with central cervical nucleus neurons projecting to the cerebellum in the cat. Brain Res. 328: 390-395.

Tracey, D. J., and B. Walmsley (1984) Synaptic input from identified muscle afferents to neurones of the dorsal spinocerebellar tract in the cat. J. Physiol. (Lond.) 350: 599-614.

Vanden Noven, S., T. M. Hamm, and D. G. Stuart (1986) Partitioning of monosynaptic Ia excitatory postsynaptic potentials in the motor nucleus of the cat lateral gastrocnemius muscle. J. Neurophysiol. 55: $569-586$.

Wiksten, B., and G. Grant (1983) The central cervical nucleus in the cat. IV. Afferent fiber connections. An experimental anatomical study. Exp. Brain Res. 51: 405-412.

Wilson, V. J., and M. Maeda (1974) Connections between semicircular canals and neck motoneurons in the cat. J. Neurophysiol. 37: 346357.

Yee, J., and K. B. Corbin (1939) The intramedullary course of the upper five cervical dorsal root fibers in the rabbit. J. Comp. Neurol. 70: 297-304 